\title{
Prevalence and associated factors of dysmenorrhea among secondary and preparatory school students in Debremarkos town, North-West Ethiopia
}

\author{
Abebaw Abeje Muluneh ${ }^{1 *}$, Tewodros seyuom Nigussie ${ }^{2 \dagger}$, Kahsay Zenebe Gebreslasie $^{3 \dagger}$,
} Kiber Temesgen Anteneh ${ }^{2+}$ and Zemenu Yohannes Kassa ${ }^{1+}$

\begin{abstract}
Background: Dysmenorrhea is one of the most common gynecologic disorders and a frequently observed cause of anxiety and discomfort among female adolescents. Its prevalence varies between 16\% and $91 \%$ in women of reproductive age. Its population statistics are too scant in Ethiopia. This study was aimed to determine the prevalence and associated factors of dysmenorrhea among secondary and preparatory school students in Debremarkos town, 2016.

Methods: Institutional based cross-sectional study was employed from Sept.26 to Oct.17, 2016 among secondary and preparatory school students in Debremarkos town. Self-administered questionnaire was used to collect data from 539 individuals selected by simple random sampling technique. Data were checked, coded and entered into Epi-data version 3.1 and exported to SPSS version 20 for analysis. Univariate, bivariate and multivariable analysis were carried out. Binary logistic regression model was computed and $P$ value $<0.05$ was considered as significant. All ethical procedures were considered.

Results: The prevalence of dysmenorrhea was $69.3 \%$. Age, $\mathrm{AOR}(95 \% \mathrm{Cl})=1.38(1.15,1.65)$, family history of dysmenorrhea, AOR $(95 \% \mathrm{Cl})=9.79(4.99,19.20)$, physical activity, $\mathrm{AOR}(95 \% \mathrm{Cl})=0.39(0.13,0.82)$, sugar intake, $\mathrm{AOR}$ $(95 \% \mathrm{Cl})=2.94(1.54,5.61)$, early menarche AOR $(95 \% \mathrm{Cl})=4.10(1.21,13.09)$, late menarche AOR $(95 \% \mathrm{Cl})=0.50(0.27$, 0.91), heavy menstrual periods $A O R(95 \% \mathrm{Cl})=2.91(1.59,5.35)$ and sexual intercourse $\mathrm{AOR}(95 \% \mathrm{Cl})=0.24(0.10 .0 .55)$ had statistically significant association with the occurrence of dysmenorrhea.
\end{abstract}

Conclusions: Age, positive family history of dysmenorrhea, physical activity, excessive sugar intake, early menarche, late menarche, sexual intercourse and heavy menstrual periods had a statistically significant association with the occurrence of dysmenorrhea.

\section{Background}

Dysmenorrhea is a pain associated with menstruation which can be abdominal pain, backache, stomach cramp, waist pain and/or thigh pain [1-4]. It can be primary, in the absence of an identifiable organic pathology, or secondary, with demonstrable pathology [5-7]. Primary dysmenorrhea usually started at or shortly after (6 to

\footnotetext{
* Correspondence: abejw16@gmail.com

${ }^{\dagger}$ Equal contributors

'Department of Midwifery, College of Medicine and Health Sciences,

Hawassa University, PO Box-1560, Hawassa, Ethiopia

Full list of author information is available at the end of the article
}

12 months) menarche, when ovulatory cycles are established $[7,8]$. The pain usually starts along with menstrual bleeding and lasts from 48 to $72 \mathrm{~h}$ [9].

Dysmenorrhea is the most commonly reported menstrual disorder [10] and one of the most common gynaecologic disorders $[11,12]$. It affects a large proportion of women of reproductive age [10]. It is usually sever enough to result in a significant socioeconomic dysfunction and disability particularly in adolescents and young women. It has a major impact on women's quality of life, work productivity, and health-care utilization [13]. It is

(c) The Author(s). 2018 Open Access This article is distributed under the terms of the Creative Commons Attribution 4.0 International License (http://creativecommons.org/licenses/by/4.0/), which permits unrestricted use, distribution, and reproduction in any medium, provided you give appropriate credit to the original author(s) and the source, provide a link to the Creative Commons license, and indicate if changes were made. The Creative Commons Public Domain Dedication waiver (http://creativecommons.org/publicdomain/zero/1.0/) applies to the data made available in this article, unless otherwise stated. 
the leading cause of morbidity leading to limitation of daily activities and recurrent school absenteeism among adolescents $[6,14]$. Generally, it has a negative impact on social, academic, and sport activities of many female adolescents $[5,15]$. Hence, failure to address dysmenorrhea causes a major social and financial burden for families, neighbors, communities and the glob at large.

Understanding the full range of dysmenorrhea among adolescent girls is a crucial point in developing appropriate management and preventive strategies. But studies on the status of dysmenorrhea and associated factors are scarce in Ethiopia. Hence, this study was aimed to determine the prevalence of dysmenorrhea and identify associated factors among secondary and preparatory school students in Debremarkos town.

\section{Methods}

\section{Study design and period}

A cross sectional study was conducted from September 26 to October 17, 2016 in Debremarkos town.

\section{Study area}

Debremarkos town is $300 \mathrm{Km}$ Northwest of Addis Ababa, the capital of Ethiopia, and $265 \mathrm{Km}$ Southeast from Bahir Dar, the Regional capital city of Amhara national regional state. Based on the 2007 population and housing census, the total population size of the town was estimated to be 62,469 of which $47.9 \%$ were male and $52.1 \%$ were females. From this, 14,618 were women in the reproductive age group [16]. Currently, there are five, four governmental and one private, secondary and preparatory schools in the town serving for a total of 7483 students of which 3564 are females.

\section{Sampling}

For this study, sample size was determined using single population proportion formula by taking the proportion of dysmenorrhea $72 \%$ in Dabat and Kolla diba [17] at 95\% confidence interval (CI) and an acceptable difference of $4 \%$.

Considering $10 \%$ none response rate, the total sample size was 539 .

There are five secondary and preparatory schools in the study area. Female students from grades 9 to 12 were included in the study. After having the list of all female students with their respective grades and sections from each school, codes were assigned for each student, and a new sampling frame was constructed. Simple random sampling technique was used. By using these numerical codes, study subjects were drown by OpenEpi, computer software.

\section{Operational definitions}

Dysmenorrhea: for this study, an adolescent was considered to have dysmenorrhea if she had one or more of abdominal pain, groin/pelvic pain, back pain or thigh pain before and/or during her menstrual periods for the last one year.

Physical activity: the habits of physical activity was measured by the participants' self-report of not at all, irregularly or regularly.

Daily allowance: participants' daily allowance was considered adequate or inadequate depending on their subjective report.

Non-academic duty: participants who didn't involve in any duty at home or outside were classified in "not at all" group; those participating in activities like home cleaning, coffee making, bed making, washing their own clothes, were grouped in "simple category"; whereas, participants involved in activities such as daily labor, marketing activities, cooking activities, farming activities were considered as "heavy".

Sugar intake: Excessive if individuals took 12 or more teaspoons of table sugar daily, Moderate if 6 to 12 teaspoons; and in a restricted use if less than 6 teaspoons [18].

Menstrual characteristics: For the purpose of this study, menstrual patterns were characterized as follows:

Long cycle: cycle repeated once every $>35$ days but $<$ 3 months, short (frequent) cycle: cycle repeated once every $<21$ days, short duration: duration of menses < 3 days, long duration: duration of period $>7$ days, and Heavy cycles were considered if a lady changes 5 or more sanitary/ vulvar pads per day but scant if one or less.

\section{Data collection}

Data were collected using a self-administered questionnaire designed in English and translated to Amharic and back to English for consistency. It has three parts, the first containing socio-demographic information of the study participants. The second part address the life style and behavioral issues including physical activity, sugar intake, coffee intake, tea intake as well as alcohol drinking, smoking and chat chewing habits. The final part was asking about reproductive issues and menstrual pattern.

The questionnaire was pre-tested on 27 (5\% of the total sample) school girls in Finoteselam town and necessary modifications were made. A one day training on the overall steps and procedures of data collection and proper data handling was provided for the data collectors and supervisor.

The data were collected by 4 female diploma teachers and supervised by one high school teacher. Voluntary assent was obtained from each participant. The questionnaire was distributed to every participant and collected on the same day to ensure confidentiality and prevent information contamination. 
Throughout the course of the data collection, regular meetings were held among the data collectors, supervisor and the principal investigator. Two more additional visits were made for participants who were not available during the first visit. The collected data were reviewed and checked for completeness before data entry and the incomplete data were discarded. Data entry template was prepared.

\section{Data analysis}

Data were checked, coded and entered to Epi-data version 3.1 and exported to SPSS (Statistical Package for Social science) version 20 for analysis. Data entry was made by the principal investigator. Texts, tables and graphs were used to present the result.

Binary logistic regression model was computed to test the presence of association between dependent and independent variables. First, bivariate analysis was computed for each predictor variable. Then, all predictor variables with $P<0.2$ were included in the multivariable analysis. Finally, significance was considered at $p<0.05$ with $95 \%$ CI.

\section{Results}

In this survey, a total of 539 individuals were included with a response rate of $94.8 \%$. Thirteen participants were not voluntary to participate and 15 questionnaires were found to be incomplete and excluded from the analysis.

\section{Sociodemographic characteristics of the respondents}

The study was conducted among 443 (86.7\%) urban and $68(13.3 \%)$ rural female secondary and preparatory school students. Their age was in the range of 14 to 24 years with the mean age of $17.55 \pm 1.62$ years. From the total respondents, 458 (89.6\%) were in the age range of 15-19 years. Five hundred four (98.6\%) of the study participants were Amhara in ethnicity and 489 (95.7\%) were followers of Orthodox Christianity. Only 18 (3.5\%) were ever married. The mean family size in which the participants have been living was $5.24 \pm 2.13$ ranging from 1 to 14 (Table 1 ).

Table 1 Socio demographic characteristics of secondary and preparatory female students in Debremarkos town, North West Ethiopia, 2016

\begin{tabular}{|c|c|c|c|}
\hline Variables & & frequency $(n=511)$ & Percent (\%) \\
\hline \multirow[t]{3}{*}{$\overline{\text { Age }}$} & $10-14$ & 6 & 1.2 \\
\hline & $15-19$ & 458 & 89.6 \\
\hline & $20-24$ & 47 & 9.2 \\
\hline \multirow[t]{4}{*}{ Religion } & Orthodox & 489 & 95.7 \\
\hline & Protestant & 16 & 3.1 \\
\hline & Muslim & 6 & 1.2 \\
\hline & ${ }^{\mathrm{a} O}$ Others & 7 & 1.4 \\
\hline \multirow[t]{5}{*}{ Mothers' educational status } & Can't read and write & 137 & 26.8 \\
\hline & Can read and write & 140 & 27.4 \\
\hline & Primary school & 64 & 12.5 \\
\hline & Secondary school & 75 & 14.7 \\
\hline & College and above & 95 & 18.6 \\
\hline \multirow[t]{4}{*}{ Participants living with } & With her parents & 406 & 79.5 \\
\hline & With her husband & 10 & 2.0 \\
\hline & Alone in a rent house & 84 & 16.4 \\
\hline & With others & 11 & 2.2 \\
\hline \multirow[t]{3}{*}{ Family size } & $\leq 4$ & 193 & 37.8 \\
\hline & $5-8$ & 279 & 54.6 \\
\hline & $\geq 9$ & 39 & 7.6 \\
\hline \multirow[t]{2}{*}{ Daily allowance $(n=492)$} & Adequate & 295 & 60.0 \\
\hline & Inadequate & 197 & 40.0 \\
\hline \multirow[t]{3}{*}{ Family history of dysmenorrhea } & Yes & 203 & 39.7 \\
\hline & No & 237 & 46.4 \\
\hline & I don't know & 71 & 13.9 \\
\hline
\end{tabular}




\section{Life style and behavioural characteristics of the respondents}

More than half (54.2\%) of the respondents didn't involve in any physical activity. Three hundred fifty seven (70\%) of the students involved in simple non-academic duties in the family. None of the respondents had smoked and used chat (Table 2).

\section{Reproductive characteristics and menstrual patterns of the participants}

The mean age at menarche was $13.16 \pm 1.76$ years with a range of 9-17 years. About half (49.7\%) of the respondents experienced menarche in the age range of 13-14 yeas. Thirty nine (7.6\%) individuals had history of sexual intercourse of which 19 (48.7\%) had history of contraceptive use. Only 1 (2.6\%) had pregnancy history. Three hundred eighty three (75\%) of the total respondents had regular menstrual cycles, of which 360 (94.0\%) had normal menstrual cycle length (21-35 days). The menstrual cycle length ranges from 14 to 40 days with the mean cycle length of $28.29 \pm 2.81$ days. The duration of menstrual flow was from 1 to 11 days with the mean of 4.41 \pm 1.60 days. Four hundred fourteen (81\%) individuals had normal duration of menstrual flow (3-6 days) (Table 3).

\section{Patterns of dysmenorrhea among the participants} Of the total 511 respondents, 354 (69.3\%) had dysmenorrhea. For $168(47.5 \%)$ and $144(40.7 \%)$ of the respondents with dysmenorrhea, the pain started 1-2 days before and just after the onset of their menses respectively. Two hundred seventy two (76.8\%) experienced dysmenorrhea during every menstrual periods (Table 4).

\section{Factors associated with dysmenorrhea}

On multivariable analysis, increasing age, AOR $(\mathrm{CI})=$ $1.38(1.15,1.65)$, positive family history of dysmenorrhea, AOR 95\% $(\mathrm{CI})=9.79(4.99,19.20)$, excessive sugar intake, AOR $(C I)=2.94(1.54,5.61)$, early menarche ( $\leq 12$ years $)$, AOR $(95 \%$ CI $)=4.10(1.21,13.09)$, late menarche $(\geq 15$ years $), \operatorname{AOR}(95 \% \mathrm{CI})=0.50(0.27,0.91)$, being sexually active, AOR $(95 \% \mathrm{CI})=0.24(0.10,0.55)$ and heavy menstrual flow, AOR $(95 \% \mathrm{CI})=2.91(1.59,5.35)$ had statistically significant association with the occurrence of dysmenorrhea(Table 5).

\section{Discussion}

The prevalence of dysmenorrhea in this study was found to be $69.3 \%$ with $95 \%$ CI of $(65.2,73.4 \%)$. This was in line with $66.8 \%$ in Debre Berhan University [2], 71.8\% in Mekelle University [10] and $72 \%$ among secondary

Table 2 Life style and behavioral characteristics of secondary and preparatory female students in Debremarkos town, North West Ethiopia, 2016

\begin{tabular}{|c|c|c|c|}
\hline Variables & & Frequency $(n=511)$ & Percent (\%) \\
\hline \multirow[t]{3}{*}{ Physical activity } & Not at all & 277 & 54.2 \\
\hline & irregularly & 175 & 34.2 \\
\hline & Regularly & 59 & 11.5 \\
\hline \multirow[t]{3}{*}{ Non-academic duty in the family } & not at all & 89 & 17.4 \\
\hline & Simple & 358 & 70.1 \\
\hline & Heavy & 64 & 12.5 \\
\hline \multirow[t]{3}{*}{ Daily coffee intake in cups } & 0 & 248 & 48.5 \\
\hline & $1-4$ & 194 & 38.0 \\
\hline & $\geq 5$ & 69 & 13.5 \\
\hline \multirow[t]{2}{*}{ Tea intake } & Yes & 489 & 95.7 \\
\hline & No & 22 & 4.3 \\
\hline \multirow[t]{3}{*}{ Drinking alcohol } & not at all & 456 & 89.2 \\
\hline & Irregularly with occasions & 36 & 7.0 \\
\hline & regularly & 19 & 3.7 \\
\hline \multirow[t]{3}{*}{ Sugar intake } & Excessive & 169 & 33.1 \\
\hline & Moderate & 330 & 64.6 \\
\hline & Minimal & 12 & 2.3 \\
\hline \multirow[t]{2}{*}{ Chronic illness } & Yes & 62 & 12.1 \\
\hline & No & 449 & 87.9 \\
\hline \multirow[t]{2}{*}{ Chronic or recurrent pelvic pain } & Yes & 17 & 3.3 \\
\hline & No & 494 & 96.7 \\
\hline
\end{tabular}


Table 3 Reproductive characteristics and menstrual patterns of secondary and preparatory female students in Debremarkos town, North West Ethiopia, 2016

\begin{tabular}{|c|c|c|c|}
\hline Variables & & Frequency $(n=511)$ & Percent (\%) \\
\hline \multirow[t]{3}{*}{ Age at menarche } & $9-12$ & 115 & 22.5 \\
\hline & $13-14$ & 254 & 49.7 \\
\hline & $15-17$ & 142 & 27.8 \\
\hline \multirow[t]{3}{*}{ Types of contraceptive used $(n=20)$} & OCPS & 9 & 45.0 \\
\hline & injectable & 6 & 30.0 \\
\hline & implants & 5 & 25.0 \\
\hline \multirow[t]{2}{*}{ Menstrual cycle pattern } & Regular & 383 & 75.0 \\
\hline & Irregular & 128 & 25.0 \\
\hline \multirow[t]{3}{*}{ Menstrual cycle length in days $(n=383)$} & $<21$ & 16 & 4.2 \\
\hline & $21-35$ & 360 & 94.0 \\
\hline & $>35$ & 7 & 1.8 \\
\hline \multirow[t]{3}{*}{ Duration menstrual flow in days } & $1-2$ & 18 & 3.5 \\
\hline & $3-6$ & 414 & 81.0 \\
\hline & $\geq 7$ & 79 & 15.5 \\
\hline \multirow[t]{3}{*}{ Amount of menstrual flow } & heavy & 181 & 35.4 \\
\hline & Normal & 292 & 57.1 \\
\hline & Light & 38 & 7.4 \\
\hline
\end{tabular}

school adolescents in Dabat and Koladiba, northwest Ethiopia [19]. It was also comparable with 65.4, 69.8 and $72.7 \%$ reported among university students in Egypt [5], Nigeria [17] and Turkey [20, 21] respectively. However, it was higher than $64 \%$ among university students in Mexico [22], 45\% among young college Nursing students in India [8] and $61.27 \%$ in Rural South Africa [23]. This difference may be explained by the sociocultural differences of the study groups in pain perception and threshold as well as the difference in life style. It was also less than that of in university of Gondar and Bahr Dar University, northwest Ethiopia [5, 24] which reported a prevalence rate of 77.6 and $85.1 \%$ respectively. This inconsistency is probably due to the fact that the

Table 4 Patterns of dysmenorrhea among secondary and preparatory school students in Debremarkos town, North West Ethiopia, 2016

\begin{tabular}{|c|c|c|c|}
\hline Patterns of dysmenorrhea & & frequency $(n=354)$ & Percent (\%) \\
\hline \multirow[t]{5}{*}{ Beginning/ starting of the pain } & $1-2$ days before the onset of menses & 168 & 47.5 \\
\hline & just after the onset of menses & 144 & 40.7 \\
\hline & a day after the onset of menses & 33 & 9.3 \\
\hline & two days after the onset of menses & 4 & 1.1 \\
\hline & 3 days before the onset of menses & 5 & 1.4 \\
\hline \multirow[t]{3}{*}{ Occurrence of the pain } & in every period & 272 & 76.8 \\
\hline & one or two periods apart & 47 & 13.3 \\
\hline & $\begin{array}{l}\text { only when periods are during exam or } \\
\text { hard working times }\end{array}$ & 35 & 9.9 \\
\hline \multirow[t]{4}{*}{ Time when the pain relieved after the onset of menses } & $<1$ day & 29 & 8.2 \\
\hline & $1-2$ days & 142 & 40.1 \\
\hline & 3-5 days & 167 & 47.2 \\
\hline & $>5$ days & 16 & 4.5 \\
\hline \multirow[t]{4}{*}{ Total duration of the pain } & $<1$ day & 41 & 11.6 \\
\hline & $1-2$ days & 111 & 31.4 \\
\hline & 3-5 days & 193 & 54.5 \\
\hline & $>5$ days & 9 & 2.5 \\
\hline
\end{tabular}


Table 5 Bivariate and multivariable analysis of factors associated with dysmenorrhea among secondary and preparatory school students in Debremarkos town, North West Ethiopia in 2016

\begin{tabular}{|c|c|c|c|c|}
\hline \multirow[t]{2}{*}{ Variables } & \multicolumn{2}{|c|}{ Dysmenorrhea } & \multirow[t]{2}{*}{ Crude OR(95\%Cl) } & \multirow[t]{2}{*}{ AOR $(95 \% \mathrm{Cl})$} \\
\hline & Yes (\%) & No (\%) & & \\
\hline Age (years) & $354(69.3)$ & 157(30.7 & $1.24(1.07,1.45)$ & $1.38(1.15,1.65)^{* *}$ \\
\hline \multicolumn{5}{|l|}{ Nonacademic duty } \\
\hline Not at all & $55(61.8)$ & $34(38.2)$ & 1.00 & 1.00 \\
\hline Simple & 245(68.6) & $112(31.4$ & $3.33(1.50,7.42)$ & $1.63(0.61,4.36)$ \\
\hline Heavy & $54(84.4)$ & 10(15.6) & $1.35(0.84,2.19)$ & $1.23(0.66,2.28)$ \\
\hline \multicolumn{5}{|c|}{ Family history of dysmenorrhea } \\
\hline Yes & 190(93.6) & $13(6.4)$ & $14.25(7.7,26.41)$ & $9.79(4.99,19.20)^{* *}$ \\
\hline No & 120(50.6) & $117(49.4)$ & 1.00 & 1.00 \\
\hline I don't know & $44(62.0)$ & $27(38.0)$ & $1.59(0.92,2.73)$ & $1.98(0.89,3.76)$ \\
\hline \multicolumn{5}{|l|}{ Habit of physical activity } \\
\hline not at all & $216(78)$ & $61(22)$ & 1.00 & 1.00 \\
\hline irregularly & 106(60.6) & 69(39.4) & $0.43(0.29,0.66)$ & $0.57(0.34,0.94)^{*}$ \\
\hline regularly & $32(54.2)$ & $27(45.8)$ & $0.34(0.19,0.60)$ & $0.39(0.19,0.85)^{*}$ \\
\hline \multicolumn{5}{|l|}{ Daily coffee intake (cups) } \\
\hline 0 & 156(62.9) & $92(37.1)$ & 1.00 & 1.00 \\
\hline $1-4$ & 135(69.6) & $59(30.4)$ & $1.35(0.91,2.01)$ & $1.63(0.99,2.67)$ \\
\hline$\geq 5$ & 63(91.3) & $6(8.7)$ & $6.12(2.58,14.8)$ & $2.13(0.47,8.36)$ \\
\hline \multicolumn{5}{|l|}{ Sugar intake } \\
\hline Excessive & $145(85.5$ & $24(14.2)$ & $3.88(2.39,6.30)$ & $2.94(1.54,5.61)^{* *}$ \\
\hline Moderate & $201(60.9$ & 129(39.1) & 1.00 & 1.00 \\
\hline In a restricted amount & $8(66.7)$ & $4(33.3)$ & $1.28(0.38,4.35)$ & $1.57(0.52,4.73)$ \\
\hline \multicolumn{5}{|l|}{ Age at menarche (years) } \\
\hline$\leq 12$ & 109(94.8) & $6(5.2)$ & $10.27(4.3,24.29)$ & $4.10(1.21,13.09)^{*}$ \\
\hline $13-14$ & $161(63.1)$ & $91(36.1)$ & 1.00 & 1.00 \\
\hline$\geq 15$ & $83(58.5)$ & $59(41.5)$ & $0.80(0.52,1.21)$ & $0.50(0.27,0.91)^{*}$ \\
\hline \multicolumn{5}{|l|}{ History of intercourse } \\
\hline Yes & $21(53.8)$ & $18(46.2)$ & $0.49(0.25,0.94)$ & $0.24(0.10,0.55)^{* *}$ \\
\hline No & $333(70.6)$ & 139(29.4) & 1.00 & 1.00 \\
\hline \multicolumn{5}{|l|}{ Duration of menstrual flow } \\
\hline$\leq 2$ & 10(55.6) & $8(44.4)$ & $0.64(0.25,1.65)$ & $0.48(0.16,1.38)$ \\
\hline $3-6$ & $274(66.2)$ & 140(33.8) & 1.00 & 1.00 \\
\hline$\geq 7$ & $70(88.6)$ & $9(11.4)$ & $3.97(1.93,8.19)$ & $1.91(0.85,4.27)$ \\
\hline \multicolumn{5}{|l|}{ Amount of menstrual flow } \\
\hline Heavy & 158(87.3) & $23(12.7)$ & $4.72(2.88,7.76)$ & $2.91(1.59,5.35)^{* *}$ \\
\hline Normal & 173(59.2) & $119(40.8)$ & 1.00 & 1.00 \\
\hline Light & $23(60.5)$ & 15(39.5) & $1.06(0.53,2.12)$ & $0.80(0.33,1.94)$ \\
\hline
\end{tabular}

prevalence of dysmenorrhea increases with age up to the pick age (24 years) where the age in Bahir Dar University ranges 17 to 24 with mean age of $20.4 \pm 1.2$ years but in this study it was $14-24$ and $17.55 \pm 1.62$ years respectively. Moreover, this difference may be resulted from the absence of universally accepted or standardized method of defining dysmenorrhea or from its subjective measurement. Furthermore, this study revealed a lower prevalence of dysmenorrhea than $73.83 \%$ reported among university students in India [14] which may be because of the sociocultural differences of the study groups in pain perception and threshold, life style and age. 
The prevalence of dysmenorrhea, in this study, increased with increasing age, AOR $(95 \% \mathrm{CI})=1.38(1.15,1.65)$. This is supported by studies conducted in Isfahan University in Iran [25], Lebanese [26] and among Mexican university students [22] which identified a statistically significant association between age and dysmenorrhea. Similarly, a highly significant difference between the ages of the women with and without dysmenorrhea was reported in Turkey [7]. However, no significant difference was observed between the mean age of women with and without dysmenorrhea in south India [27]. The inconsistency might be because of the difference in the age of the study participants. The age in this study was from 14 to 24 year, but it was from 11 to 28 years in south India which include both the age ranges below and above the pick age.

This study identified a statistically significant association between the occurrence of dysmenorrhea and positive family history of dysmenorrhea, AOR (95\% CI) 9.79 $(4.99,19.20)$. This is consistent with the findings of similar studies in Serbia [1], Turkey [10, 20, 21], India [11], Lebanese [25], Mekelle [10] and Bahir Dar Universities in Ethiopia [24]. This is probably related to genetic factors, which needs further studies.

In this study, physical activity was found to have a statistically significant association with the occurrence of dysmenorrhea, AOR $(95 \% \mathrm{CI})=0.399(0.19,0.85)$, which was consistent with the findings in a systematic review of randomized controlled trials, which confirms as exercise reduces the symptoms associated with dysmenorrhea [28]. But, no statistically significant association was observed between physical activity and dysmenorrhea in Egypt [4]. The difference may be because of measurement difference; i.e. in this study physical activity was measured by self-report of the participants' habit of physical activity as not at all, irregularly or regularly, where as in Zagazig University, Egypt participants were asked as if they were athletes, active in physical activity or sedentary.

In this study, a statistically significant association between excessive sugar intake and the presence of dysmenorrhea was observed, AOR $(95 \% \mathrm{CI})=2.94(1.54,5.61)$, which was similar with the result of a cross-sectional surveys in Turkey [20]. This is also supported by statistically significant association between dysmenorrhea and consumption of more than four glasses of tea per day among Debre Berhan University students in Ethiopia [12]. This is probably because food items reach in sugar may contain the precursors of prostaglandins which are presumed to be the cause of dysmenorrhea. This requires further investigations.

A statistically significant association between age at menarche and dysmenorrhea was identified in this study. This was supported by studies conducted among high school students in Mexico, and university students in
Mexico, Serbia, Palestinian and Egypt [1, 2, 4, 22]. Early menarche was related to an increase in the prevalence of dysmenorrhea, AOR $(95 \% \mathrm{CI})=4.10(1.21,13.09)$. Whereas, late menarche was associated with the decrease in the prevalence of dysmenorrhea, AOR $(95 \% \mathrm{CI})=0.50(0.27$, 0.91). This is also supported by the thought that dysmenorrhea is caused by the release of inflammatory factors during menstruation [29] and started after the establishment of ovulatory menstrual cycles [30].

In this study, a statistically significant association between the presence of dysmenorrhea and heavy menstrual flow was observed, AOR $(95 \% \mathrm{CI})=2.91(1.59,5.35)$, which was consistent with a report among Mexican high school students [2], Heavy menstrual flow was related to increased prevalence of dysmenorrhea which is also in line with the thought that dysmenorrhea is caused by the release of inflammatory factors during menstruation [29]. This is further strengthened by a more likelihood of having dysmenorrhea during long menstrual flow periods in Mekelle University [10].

\section{Limitations of the study}

Readers, please note that since most variables in this study were measured by the participants' subjectivereport, observation and recall bias may be introduced.

\section{Conclusions}

The prevalence of dysmenorrhea among secondary and preparatory school students in Debremarkos town was high.

Dysmenorrhea was more common with increasing age, among ladies with positive family history of dysmenorrhea, excessive sugar intake habit, early menarche and those having heavy menstrual periods. Whereas, physical activity, late menarche and sexual intercourse were found to be protective factors for the occurrence of dysmenorrhea.

\section{Abbreviations}

AOR: Adjusted Odds Ratio; Cl: Confidence Interval; OR: Odds Ratio

\begin{abstract}
Acknowledgements
The authors would like to thank our data collectors and supervisor for their invaluable effort. Our deepest gratitude also goes to our study participants for their voluntary participation. We are also grateful for school administrators and staff of secondary and preparatory schools in Debremarkos town for their cooperation, help and encouragement during the data collection. Finally, we would like to thank College of Medicine and Health Sciences, University of Gondar for giving this chance.
\end{abstract}

\section{Funding}

There was no any funding or sponsoring organization for this paper.

Availability of data and materials

We have sent all the available data and we do not want to share the raw data as we are doing related study. 


\section{Authors' contributions}

AA wrote the proposal, participated in data collection, analysed the data and drafted the paper. TS, KZ, KT and ZY approved the proposal with some revisions and participated in data analysis. All the authors revised the subsequent drafts of the paper and read and approved the final manuscript.

\section{Ethics approval and consent to participate}

Ethical clearance letter was first obtained from Institutional Review Board (IRB) of the University of Gondar and presented to Debremarkos town education bureau to obtain an official permission. The investigator then communicated to each school and grant permission. Finally, each participant gave their informed written consent or parents and/or guardians provided consent on behalf of participates below 18 years old. Confidentiality was assured by making the questionnaire anonymous.

\section{Competing interests}

The authors declare that they have no competing interests.

\section{Publisher's Note}

Springer Nature remains neutral with regard to jurisdictional claims in published maps and institutional affiliations.

\section{Author details}

'Department of Midwifery, College of Medicine and Health Sciences, Hawassa University, PO Box- 1560, Hawassa, Ethiopia. ²Department of Midwifery, College of Medicine and Health Sciences, University of Gondar, PO Box-196, Gondar, Ethiopia. ${ }^{3}$ Department of Midwifery, College of Health Sciences, Mekelle University, PO Box- 1871, Mekelle, Ethiopia.

\section{Received: 5 April 2017 Accepted: 17 April 2018}

Published online: 24 April 2018

\section{References}

1. Adinma ED, Adinma J. Perceptions and practices on menstruation amongst Nigerian secondary school girls. Afr J Reprod Health. 2008;12(1):74-83.

2. Ortiz Ml, Rangel-Flores E, Carrillo-Alarcón LC, Veras-Godoy HA. Prevalence and impact of primary dysmenorrhea among Mexican high school students. Int J Gynecol Obstet. 2009;107(3):240-3.

3. Hillen TI, Grbavac SL, Johnston PJ, Straton JA, Keogh JM. Primary dysmenorrhea in young western Australian women: prevalence, impact, and knowledge of treatment. J Adolesc Health. 1999;25(1):40-5.

4. Nooh AM. Menstrual disorders among Zagazig University students, Zagazig, Egypt. Middle East Fertil Soc J. 2015;20(3):198-203.

5. French L. Dysmenorrhea. Am Fam Physician. 2005;71(2):285-91.

6. Davis AR, Westhoff CL. Primary dysmenorrhea in adolescent girls and treatment with oral contraceptives. J Pediatr Adolesc Gynecol. 2001;14(1):3-8.

7. Osayande AS, Mehulic S. Diagnosis and initial management of dysmenorrhea. Am Fam Physician. 2014;89(5):341-6.

8. Shah M, Monga A, Patel S, Shah M, Bakshi H. A study of prevalence of primary dysmenorrhea in young students-a cross-sectional study. Indian J Community Med. 2013;4(2):30-4.

9. Deligeoroglou E, Tsimaris P. Menstrual disturbances in puberty. Best Pract Res Clin Obstet Gynaecol. 2010;24(2):157-71.

10. Aktas D. Prevalence and factors affecting dysmenorrhea in female university students: effect on general comfort level. Pain Manage Nurs. 2015;16(4):534-43.

11. Omidvar S, Bakouei F, Amiri FN, Begum K. Primary dysmenorrhea and menstrual symptoms in Indian female students: prevalence, impact and management. Global J Health Sci. 2015;8(8):135.

12. Ylikorkala O, Dawood MY. New concepts in dysmenorrhea. Am J Obstet Gynecol. 1978;130(7):833-47.

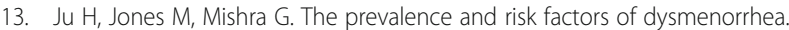
Epidemiol Rev. 2014;36:104-13.

14. Singh A, Kiran D, Singh $H$, Nel B, Singh P, Tiwari P. Prevalence and severity of dysmenorrhea: a problem related to menstruation, among first and second year female medical students. Indian J Physiol Pharmacol. 2008; 52(4):389-97.

15. Banikarim C, Chacko MR, Kelder SH. Prevalence and impact of dysmenorrhea on Hispanic female adolescents. Arch Pediatr Adolesc Med. 2000;154

16. Encyclopaedia of Debre-Markos town administration. Socioeconomic characteristics; 2011.
17. Amaza DS, Sambo N, Zirahei JV, Dalori MB, Japhet H, Toyin H. Menstrual pattern among female medical students in University of Maiduguri, Nigeria. Br J Med Med Res. 2(3):327-37. 2012 Jul-Sep

18. World Health Organization. Guidlines: sugars intake for adults and children. Geneva: World Health Organization; 2015.

19. Zegeye DT, Megabiaw B, Mulu A. Age at menarche and the menstrual pattern of secondary school adolescents in Northwest Ethiopia. BMC Womens Health. 2009;9(1):1-8.

20. Ozerdogan N, Sayiner D, Ayranci U, Unsal A, Giray S. Prevalence and predictors of dysmenorrhea among students at a university in Turkey. Int J Gynecol Obstet. 2009;107(1):39-43.

21. Unsal A, Ayranci U, Tozun M, Arslan G, Calik E. Prevalence of dysmenorrhea and its effect on quality of life among a group of female university students. Ups J Med Sci. 2010;115(2):138-45.

22. Ortiz Ml. Primary dysmenorrhea among Mexican university students: prevalence, impact and treatment. Eur J Obstet Gynecol Reprod Biol. 2010; 152(1):73-7.

23. Oni TH, Tshitangano TG. Prevalence of menstrual disorders and its academic impact amongst Tshivenda speaking teenagers in rural South Africa. J Hum Ecol. 2015;51(1,2):214-9.

24. Shiferaw MT, Wubshet M, Tegabu D. Menstrual problems and associated factors among students of Bahir Dar University, Amhara National Regional State, Ethiopia: a cross-sectional survey. Pan Afr Med J. 2014;17

25. Habibi N, Huang MSL, Gan WY, Zulida R, Safavi SM. Prevalence of primary dysmenorrhea and factors associated with its intensity among undergraduate students: a cross-sectional study. Pain Manage Nurs. 2015; 16(6):855-61.

26. Santina T, Wehbe N, Ziade F. Exploring dysmenorrhoea and menstrual experiences among Lebanese female adolescents. Eastern Mediterr Health J. 2012;18(8):857-63.

27. Omidvar S, Bakouei F, Amiri FN, Begum K. Primary dysmenorrhea and menstrual symptoms in Indian female students: prevalence, impact and management. Glob J Health Sci. 2016;8(8):53632.

28. Brown J, Brown S. Exercise for dysmenorrhoea. Cochrane Database Syst Rev. 2010;(2):Cd004142.

29. Balbi C, Musone R, Menditto A, Prisco LD, Cassese E, D'Ajello M, et al. Influence of menstrual factors and dietary habits on menstrual pain in adolescence age. Eur J Obstet Gynecol Reprod Biol. 2000;91(2):143-8.

30. Harel Z. Dysmenorrhea in adolescents and young adults: etiology and management. J Pediatr Adolesc Gynecol. 2006;19(15):363-71.

\section{Ready to submit your research? Choose BMC and benefit from:}

- fast, convenient online submission

- thorough peer review by experienced researchers in your field

- rapid publication on acceptance

- support for research data, including large and complex data types

- gold Open Access which fosters wider collaboration and increased citations

- maximum visibility for your research: over $100 \mathrm{M}$ website views per year

At BMC, research is always in progress.

Learn more biomedcentral.com/submissions 